\title{
Becoming Enviroment_becoming post animist: Life is an Utopia
}

\author{
Keywords \\ Performance, Public Space, Post Animism, Post modern Animism, Ma.
}

In this article, I present case studies of the urban interventions, installations and performances for public space of my art series entitled 'Life is an Utopia', through the practice of the concept becoming environment and its variation, becoming post animism. 'Life is an Utopia' is an artistic research and a series of artworks in which I aim to discuss social-political-environmental-cultural contemporary issues through an aesthetic perspective and poetic practices. I propose a critical exercise in the cross boundaries of sound art, audiovisual performance, performance, installation and urban intervention, that questions the growing devaluation of life in face of the financial market, manifested in the recent environmental catastrophes and the systematic dismantling of social and human rights in Brazil. Based on propositions of counter position between the blunting and the contemplative, in the series I explore the Japanese cultural term 'Ma' as an opening to the environment, to everything that surrounds us and we do not control, proposing a critical view of the system through a resilient perspective. For this occasion, I will present the performance for public space entitled 'ISLAND :: Life is an Utopia', whose artistic research discusses our relation with nature through a reflection about the importance of water in our lives. In that sense, based in the concept of post-animism or post-modern animism of the Japanese sociologist Shoko Yoneyama, and the cosmological and animist perspectives of the Brazilian indigenous intellectuals Ailton Krenak and Davi Kopenawa, I practice the concepts of becoming environment and becoming post animist as forms of poetic and aesthetic assemblages of public life and its countless socio-political-environmental implications in the relationship between human kind and nature, society and spirituality, body and soul, and community, spirituality and nature. I aim to problematize the discussion about spirituality, coloniality, post animism, Amerindian animism and socio-political-environmental responsibility for the disasters, in order to deepen the understanding concerning the creative process and artistic research of the art series and the artwork ISLAND. In this context, I will draw a line of flight between socio-political-environmental aspects around the Fukushima Nuclear accident and the recent environmental disasters in Brazil, especially the oil stains that hit the northeastern coast and the ruptures of the Mariana and Brumadinho dams, starting from the perspective of silence and $\mathrm{Ma}$ as a form of political resistance and resilience. 